$\checkmark$ Research Square

\title{
Knowledge of Nurses About the End of Life Care Towards Terminal Illnesses: a Cross-sectional Design
}

Maha Subih ( $\square$ maha.subih@zuj.edu.jo)

Al-Zaytoonah University of Jordan

\section{Rasmieh AL-amer}

Isra University

Domam Alomari

Al-Ghad International Health Sciences Colleges

Duncan C Randall

University of Southampton

Rima Darwish

Jordanian Royal Medical Services

Sultan Mosleh

Mutah University

\section{Research Article}

Keywords: end-of-life care, Jordan, knowledge, nurses, terminal illnesses

Posted Date: February 19th, 2021

DOI: https://doi.org/10.21203/rs.3.rs-211220/v1

License: (9) (i) This work is licensed under a Creative Commons Attribution 4.0 International License.

Read Full License 


\section{Abstract}

The preparedness of nurses in relation to providing palliative care is not always adequate, indeed, it is sometimes unsatisfactory; this may be caused by lack of knowledge and limited experience in end-of-life care. The purposes of the study were to assess the levels of registered nurses' knowledge about end of life care (EOLC), examine the relationships between EOLC knowledge and demographic variables, and explore predictors of EOLC knowledge. A cross-sectional design survey was conducted on Jordanian registered nurses $(\mathrm{N}=220)$. Data analysis included descriptive statistics, correlation, and multiple regression.

The results showed that End-of-Life Professional Caregiver Survey (EPCS) mean total score was moderate to high (72.1 (SD \pm 13.6 ), Range 0-112). For EPCS subscales: Patient and family-centered communication, cultural and ethical values were moderately high, while effective care delivery subscale was low. Predictors were attending training in palliative care $(p=0.02)$, and working in the intensive care unit $(p=0.04)$. Thus, nurses need palliative care education, more attention is required in palliative care education on clinical skills, as well as weakness of effective care delivery. Also build palliative education into the core nursing curriculum.

\section{Introduction}

The aim of palliative care is to maximizing quality of life for terminally ill patients and their families, by using all measures that predict, manage, and inhibit suffering. This care provided through the continuum of illnesses including physical, psychosocial, emotional, and spiritual needs ${ }^{1}$.

The provision of palliative care services to patients in need is rapidly rising on a global scale. This stems from the fact that chronic diseases are major health threats in this contemporary world ${ }^{2}$. Chronic health conditions (e.g., cancer, chronic respiratory diseases, cardiovascular diseases, and diabetes mellitus) often require palliative care services. For the purpose of this study, a terminal illness is described as "an incurable disease that cannot be adequately treated and is reasonably expected to result in the death of the patient" 3 .

It is important that healthcare providers (HCPs), especially nurses, are well prepared with related information and high therapeutic communication skills that support the principles of palliative care. The literature review validated that there was a lack of knowledge among most nurses in providing quality palliative care in diverse clinical practice settings, also palliative care training among nurses was inadequate and inconsistent ${ }^{4}$. This can lead to challenges, such as a lack of practice in end-of-life care (EOLC) (lack of skills in providing care), a lack of participation in the patient's care plan, and poor knowledge.

Nurses deal with death and dying in all hospital setting, therefore, courses of EOLC courses must engaged in the graduate nursing curricula to teach students how to provide and improve the quality of 
EOLC ${ }^{5}$. End-of-Life Nursing Education Consortium is one of the most effective end-of-life (EOL) education projects providing planned information to nurses ${ }^{6}$.

Teaching professional nurses' palliative care/ EOLC requires serious efforts that emphasizes different methods in teaching, such as role play, and interactive teaching ${ }^{7}$. However, in Jordan, the curriculum of the bachelor degree in nursing lacks competencies regarding palliative care skills, and the courses that are offered in this respect are optional ${ }^{8}$.

Nurses should know their patients' preferences and wishes in order to be able to provide suitable EOLC and it is crucial that these concerns are discussed with patients and/or their family members ${ }^{9}$. Such discussions may avoid both needless hospitalization and useless treatment, and thus assist (EOL) decision-making processes ${ }^{9}$.

Nurses who lack knowledge and awareness about palliative care cannot offer proper skills to evaluate patients' needs, and so they cannot be assigned to palliative care units ${ }^{4}$. Moreover, EOL studies have frequently discussed the experiences of nurses working in specialty units, such as critical care, palliative care, and oncology, but have rarely explored EOLC in other ordinary units ${ }^{10}$.

Nurses can get use of ongoing in service education about EOLC to enhance patients' quality of life and decrease their suffering in addition to their families ${ }^{4}$. Nurses in critical care units had to be involved in such training to override obstacles/barriers of administering palliative care ${ }^{11}$. One of these barriers is palliative care lack of knowledge ${ }^{12}$.

In Jordan, a developing country, the need for palliative care is increasing, as a consequence of the increasing prevalence of non-communicable diseases, which account for nearly $76 \%$ of all deaths ${ }^{8}$. For example, cardiovascular diseases and cancer are becoming an increasing burden on the Jordanian health system, and they are the main causes of death with $36 \%$ and $15 \%$, respectively ${ }^{8}$. Importantly, the healthcare system in Jordan lacks a national care policy in relation to palliative care services, hence a large number of people with chronic diseases are not able to access such services ${ }^{8}$.

Further, a study conducted by Omran and Obeidat ${ }^{13}$ claimed that palliative care nursing began in Jordan with the initiation of the Jordan Palliative Care Initiative in 2001. This initiative formed a foundation for establishing the first unit at the King Hussein Cancer Center in 2004, and palliative care services were provided in hospital and home settings. Recognizing the importance of palliative care, the Jordan Palliative Care Society, an agency committed to providing palliative care training and education, recommended the incorporation of palliative care early in the course of a chronic disease along with curative therapy plans ${ }^{14}$. Nevertheless, Jordanian nursing schools provide palliative education as elective courses, hence not all students are exposed to this kind of education and training ${ }^{13}$.

This study's aims were: To assess the level of registered nurses' knowledge about EOLC and examine the relationship of knowledge of EOLC with a specific demographic variable, then explore the predictors of 
EOLC knowledge.

\section{Methods}

\section{Design}

This study used a cross-sectional design. All methods were performed in accordance with the relevant guidelines and regulations

\section{Sample and setting}

G-power, version (3.0.10), was used to calculate the study sample; the total calculated sample needed (with alpha $\leq 0.05$, power set at 0.90 , and medium size effect, predictors $=7$ ), showed a minimum sample size was 130 participants. In this study, a convenience sample of 220 registered nurses out of 250 questionnaires distributed (response rate $88 \%$ ), agreed to participate and fill the questionnaires over a 3month period from June to August 2018.

The eligibility criteria for the study included being a registered Jordanian nurse who was; working in clinical settings, including intensive care units (ICUs), oncology departments, medical/surgical floors, and emergency room (ER); also working with terminally ill patients at a hospital setting for at least 12 months prior to data collection to ensure that the study subjects will provide relevant data in relation to EOLC. All health sectors in Jordan were involved in the sample from Amman, the capital, and Irbid (north), including governmental, private, military, and educational hospitals.

\section{Measurements}

The present study used a two-part questionnaire, which is described as follows:

\section{1) Sociodemographic data}

The sociodemographic questionnaire was developed by the researchers and based on the existing literature $4,7,15,16$, and it is composed of questions about age, gender, type of university they graduated from (governmental or private), type of hospital, years of experience in nursing, unit they work at (ICU- ERmedical/surgical floor- oncology department), and having EOLC/palliative training courses or not.

\section{2) The level of nurses' knowledge about EOLC}

The End-of Life Professional Caregiver Survey (EPCS) was used ${ }^{17}$. This is a 5 -point Likert scale with a response format from zero (not at all) to 4 (very much), with a total score of 112; the higher the score the better the knowledge and comfort in providing EOLC. This tool consists of 28 items with three subscales including: 1) patient and family-centered communication (PFCC), 12 items; 2) cultural and ethical values (CEV) eight items; and 3) effective care delivery (ECD), eight items ${ }^{17}$. 
The cut-offs for total score of EPCS regarding level of knowledge and comfort in providing EOLC used are as follows: 0-21, not at all; 22-44, a little bit of knowledge and comfort; 45-67, some knowledge and comfort; 68-90, quite a lot of knowledge and comfort; 91-112, a very high EOL knowledge and comfort 17. For subscale scores' range, PFCC from 0-48, CEV scores from 0-32, and for ECD from 0-32. On a scale of $0-4$, Category 0 represented perceptions of low EOL knowledge, whereas Category 4 represented perceptions of high EOL knowledge ${ }^{4}$.

This scale was validated in a large multidisciplinary study among physicians, nurses, and social workers 17. Content validity of the EPCS in this study was confirmed by three palliative experts (two academic doctorate holders of palliative care in nursing, and one palliative physician) and yielded content validity index (CVI) 0.90 , while reliability was measured by using Cronbach's alpha, which was $(a=0.90)$. For each subscale, a Cronbach's alpha was; PFCC $(a=0.80)$; CEV $(a=0.80)$; ECD $(a=0.84)$.

\section{Translation of the End-of-Life Professional Caregiver Survey (EPCS)}

After acquiring permission to use the tool (EPCS) from the original authors, the translation was conducted by a panel of palliative care experts, two clinicians, two nurses who work with terminal ill patients, and two laypeople who are proficient in both the Arabic and English language were asked to translate the survey using the forward and backward technique. After that, the panel discussed any discrepancies that emerged between the original version and the translated version of the survey until consensus was reached and a final version of the Arabic EPCS was produced. The final Arabic version of the EPCS was piloted with 30 nurses who met the inclusion criteria for the participants in order to verify the feasibility and the practicality of the survey.

\section{Ethical consideration}

Permission was obtained from the Ethical Research Committee at Al-Zaytoonah University of Jordan (Institute Review Board (IRB) no: 19/170/2018) and by each participating hospital IRB committee. Datasets available in the corresponding author office on reasonable request.

\section{Data collection procedure}

The main researcher approached the head nurses of each unit to facilitate data collection and to identify the nurses eligible for the study. Thereafter, two of the researchers approached the potential participants at their clinical premises and explained the purpose of the study. Nurses who agreed to participate were provided with a self-sealed envelope that contained the questionnaires, a written consent form to sign, and a cover sheet that included clear instructions about the study, the participants' rights, and the contact details of the main researcher. The researchers asked the study subjects to put the completed survey into the envelope and seal it to ensure the confidentiality and their anonymity. Researchers informed the participants that they would come back after 2 weeks to collect the survey. Researchers made a call two days before collecting the survey to make sure that the participants were ready to hand it in. 


\section{Data analysis}

Data analysis and management was undertaken using SPSS version 21.0. Continuous variables were described using descriptive statistics (percentages, mean, and standard deviation (SD)). Correlation coefficient test was used to examine the direction and the magnitude of the relationship between specific demographic factors and EPCS scores. Then multiple regression hierarchy was used to find the predictors.

\section{Results}

Out of 250 nurses invited to take part in this study, 220 completed and returned the questionnaire. The majority of the study participants were males $(56.8 \%)$, married (61\%), and had completed a bachelor's degree in nursing (85\%). Most participants worked in ICU (59.5\%). The average age of participants was 29 (SD \pm 5.1 ) years, with a range of 22 to 55 years. The average years of experience was $6.3(S D \pm 4.6)$ years, with a range of 1 to 30 years. Only $12.3 \%$ had attended training courses in palliative or EOLC (Table $1)$.

Moderate knowledge of EOLC was found among more than half of the participants. Total scores ranged from 36-112, mean total score was 72.1 (SD \pm 13.6 ), which is considered as moderately knowledgeable. For EPCS subscales: PFCC mean was 31.8 (SD \pm 6.2 ) out of 48, CEV mean was 21.9(SD \pm 4.4 ) out of 32, both of which are considered as moderately knowledgeable, while ECD mean was 18.6(SD \pm 5.5$)$ out of 32 , which is considered relatively low (Tables $2 \& 3$ ).

A significant correlation was found between EPCS and taking educational training in palliative care or EOLC $(r=0.16, p=0.03)$ (Table 4). Those who had training courses were found to have significantly higher EPCS mean scores compared to those who had no previous training, by conducting an independent $\mathrm{t}$-test (77.8 vs. 71.3 respectively, $\mathrm{t}=-2.25, p=0.01$ ). Also comparison between (ICU nurses and non-ICU nurses) using an independent t-test found insignificant difference between means (73.3 vs. $70.4, t=1.52, p=0.2$ ), respectively.

Multiple hierarchical regression was used to find the predictors, with seven demographic variables entered (after modifying some to dichotomous variables). The overall regression was statistically significant, $R=0.25, R^{2}=0.06$, adjusted $R^{2}=0.032, F(6,196)=2.103, p=0.05$. So these variables predicted just $6 \%$ of the variance. The only significant predictors were the unit (ICU nurses had higher scores in knowledge of EOLC than non-ICU nurses) ( $p=0.04$ ), and taking training courses in EOLC/palliative care $(p=0.02)$, with those who had undergone training courses having higher scores of knowledge than those who had not (Table 5).

\section{Discussion}

This cross-sectional survey of 220 Jordanian nurses across various clinical settings found moderate to high knowledge of communication with patients/families and cultural and ethical values associated with 
EOLC, however, knowledge relating to effective care delivery was low. Key predictors included palliative care training and working in the ICU.

The results of this study indicated that around $64 \%$ of the study participants perceived themselves as having moderate knowledge and comfort in providing EOLC; they are not experts but at the same time they are not without some measure of capability. These results are similar to previous studies ${ }^{18-20}$. This is not surprising result knowing that Jordan has limitation in nursing curriculum regarding EOLC and palliative care subject.

However, EOLC has started to be infused in the nursing curricula in Jordan, but only theoretically, without any clinical implementation for this type of care. Some hospitals in Jordan provide nurses with continuous educational programs that involve materials related to EOLC services. If provided with the opportunity to improve their EOL care abilities, all nurses potentially could benefit. On the other hand, some other nurses perceived themselves less confident in treating the terminally ill and lacked the necessary knowledge and skills to provide care for these patients 7,21 .

Jordan has an Arabic Islamic culture but religious freedom is adopted, which shapes the Jordanian beliefs, with religious and spiritual aspects treated as important issues for patients. Cultural context might account for the participants' higher scores in the CEV and PFCC subscales. Religiousness was associated strongly with a greater desire to initiate EOL discussions when indicated ${ }^{22}$. Recognizing and addressing cultural and religious/spiritual values is a critical aspect of providing goal-concordant care for patients facing a serious illness, especially at the end of life ${ }^{23}$.

Higher scores were among family-centered communication and with cultural and ethical values. Turning to the ECD items, which focus on familiarity and effectiveness of palliative and EOLC, our study found that participants had the lowest score within the ECD domain, suggesting that there is a critical need in terms of systematic and comprehensive education, in particular in the clinical/practical domain. This is highly recommended knowing that the majority of the sample was young nurses and still at junior level. This is consistent with many studies ${ }^{19,20,24}$, which is not surprising since the participants had limited experience in EOLC and Jordan is a developing country in palliative care and EOLC.

However, other studies reported that nurses had high level of self-confidence with the physical needs of EOLC, but still need essential skills for more holistic care; it has also been stated that nurses who accomplish educational training on palliative care had higher scores in EOLC knowledge and attitudes ${ }^{25}$, 26.

Importantly, the study revealed a significant relationship between educational programs in palliative care /EOLC and the level of knowledge, although only a few of these nurses had been on training programs in palliative/EOLC. These findings are consistent with the literature, which found that educational workshops significantly increased the nurses' knowledge and attitudes in relation to providing EOLC services ${ }^{7,18,28}$. On the other hand, the formal educational preparation of nurses did not appear to be 
associated with their perceptions of EOLC knowledge. This lack of association confirmed what has been reported in other studies: nurses receive little formal education about EOL care across all levels of education ${ }^{7}$.

Years of experience and age had no effect on nurses' confidence level with their knowledge and skills regarding EOLC in this study. Similar results have been found ${ }^{24,27}$. However, Moir et al.'s study ${ }^{20}$ in the United States found that the more their experience (in years) the more confident nurses feel in discussing palliative care with patients and families. Hou et al., in China reached the same conclusion ${ }^{21}$.

The likely explanation for our results is that most nurses were young and junior. Nurses gradually develop knowledge about EOLC with time, until either hitting a plateau, or continuing to develop more knowledge and skills if offered continuous educational programs ${ }^{19}$.

The type of work unit had significant prediction for EOLC knowledge in which ICU nurses had higher scores of knowledge in comparison with non-ICU nurses. Reasons may include following specific guidelines and evidence-based resources, which may not available to other units' nurses also ICU staff may gain knowledge from each other ${ }^{5}$. Nurses in ICU are in constant touch with dying patients compared with other department's nurses, also due to different hospitals and units' policies towards palliative care 5 .

This is inconsistent with some studies in Palestine ${ }^{25}$ and in the United State ${ }^{4,7}$. However, one study states that oncology nurses had the highest level of knowledge based on EPCS scores ${ }^{20}$. The same result was found with cardiac care unit nurses in China, in which ICU nurses had the highest level in EOLC knowledge 21 .

\section{Implications}

The findings of this study can inform stakeholders, including health policymakers, on the development of evidence-based policies and procedures related to updated practices, preceded by obtaining resources and offering staff education.

For clinician's implications, it shows the importance of consistent communication by all members of the multidisciplinary team and patients and their families. A well-educated workforce will provide individualized, compassionate care satisfying the physical, emotional, social, and spiritual needs of patients and families.

Regarding academic educators need to build palliative care to nursing curricula, with more concentration on the clinical part of how to provide EOLC. Clinically, this should include the need to develop programs to improve the capacity of nurses to deliver effective interventions to terminally ill patients. Also, hospitals must concentrate more on continuous educational programs that include palliative care. 
More studies are required that consider the impact of religion and religious beliefs in end-of-life care. In addition, further research is needed in this area, with larger samples of oncology and medical-surgical nurses to determine whether findings from this study of nurses' perceptions are generalizable to larger groups of nurses from other units in comparison with nurses in ICU.

\section{Limitations}

This study has some limitations that need to be considered in order to make the interpretation of the data more reliable. This study adopted a cross-sectional design which precludes causality. Further, the study recruited a convenient sample, hence we believe that only motivated participants took part in this study, so generalization cannot be conducted, and results should be interpreted with caution. Additionally, we used self-reporting scales, and this is known to increase the likelihood of social desirability bias as well as recall bias.

\section{Conclusion}

This study shows a moderate level of perceived skill, with a need for additional knowledge. The findings are of key importance for palliative care. It provides evidence of the need for effective communication with patients and their families about palliative and EOLC. It is crucial to integrate palliative care education, especially with regard to EOLC, into continuing education courses in addition to undergraduates' curriculum in nursing schools. Not having EOLC/ palliative care skills increases the possibility of negative patient outcomes. It also enhances the transition from a curative to a palliative approach, which is a challenge for both the nurses and patients. Nurses developing skills and knowledge in this area will enable them to help patients and their families make smoother transitions.

\section{Declarations}

\section{Author contributions:}

Conceptualization and Project administration: MS

Data collection and entry: RD

Formal analysis: MS

Methodology: RA

Roles/Writing: MS, DA and SM

Review \& editing: DA and DR

\section{Funding:}

This research did not receive any specific grant from funding. 


\section{Conflict of interest:}

The authors declared that they have no competing interests.

\section{Ethical issues:}

None to be declared

\section{References}

1. National Hospice and Palliative Care Organization. Explanation of Palliative Care. Available from: https://www.nhpco.org/palliative-care-overview/explanation-of-palliative-care/. (2019)

2. World Health Organization. Palliative care .Available from: https://www.who.int/news-room/factsheets/detail/palliative-care (2018).

3. Hui D, Bruera E. Integrating palliative care into the trajectory of cancer care. Nat Rev Clin Oncol; 13(3):159-71(2016).

4. Chan B. An Evaluation of the Influence of the Care (Compassion and Respect at the End-of-Life) Program on Registered Nurses' Knowledge snd Comfort About End-of-Life Care and Care Delivery for Patients with Life-Limiting Illnesses: Azusa Pacific University; Feb, 2018.

5. Mani, Z.A. Intensive care unit nurses experiences of providing end of life care. Middle East $J$ Nurs; 10(1), pp.3-9(2016).

6. American Association of Colleges of Nursing (AACN). ELNEC fact sheet. Available from www.aacn.nche.edu/ elnec/about/fact-sheet (2016).

7. Gaffney MK. Critical Care Nurses' Perceptions of Their Knowledge and Self-Efficacy About Providing End-of-Life Care. Minneapolis, Minnesota: Walden University; published thesis, (2015).

8. Qadire M, Omran S, Tayyem M. Palliative cancer care in Middle Eastern countries: accomplishments and challenges. Nova Science Publishers, Inc. Chapter 9: Palliative care in Jordan: accomplishments and challenges, 111-123 (2014).

9. Gjerberg E, Lillemoen L, Førde R, Pedersen RJBg. End-of-life care communications and shared decision-making in Norwegian nursing homes-experiences and perspectives of patients and relatives. BMC Geriatr, 15(1):103(2015).

10. Wilson, Janet, and Marilyn Kirshbaum. Effects of patient death on nursing staff: a literature review. Br J Nurs; 20.9, 559-563(2011).

11. Perrin KO, Kazanowski M. Overcoming Barriers to Palliative Care Consultation. Crit Care Nurse; 35(5):44-52(2015).

12. Beckstrand RL, Collette J, Callister L, Luthy KE. Oncology nurses' obstacles and supportive behaviors in end-of-life care: providing vital family care. Oncol Nurs Forum; 39(5):E398-406(2012).

13. Omran S, Obeidat R. Palliative Care Nursing in Jordan. J Palliat Care Med; S4:005:1-4(2015). 
14. Abu Sharour L. Lived experience of Jordanian colorectal cancer patients with recurrence: an interpretative phenomenological analysis. Psychol Health Med ; 24(7):827-35(2019).

15. Iranmanesh S, Razban F, Tirgari B, Zahra GJP, care s. Nurses' knowledge about palliative care in Southeast Iran. Palliative \& supportive care,12(3):203-10(2014).

16. Lee J, Choi M, Kim Ss, Kim H, Kim Dooree. Korean nurses' perceived facilitators and barriers in provision of end-of-life care. IJNP, 19(3):334-43(2013).

17. Lazenby M, Ercolano E, Schulman-Green D, McCorkle R. Validity of the End-of-Life Professional Caregiver Survey To Assess for Multidisciplinary Educational Needs. J Palliat Med, 15(4):42731(2012).

18. Corcoran K. Evaluation of an Educational Workshop to Increase Comfort Level of Professional Caregivers with End-of-Life Care. Medsurg Nursing; 25(2):103-9(2016).

19. Kaasalainen $\mathrm{S}$, et al. What are the differences among occupational groups related to their palliative care-specific educational needs and intensity of interprofessional collaboration in long-term care homes? BMC Palliat Care;16:33(2017).

20. Moir $C$, et al. Communicating with patients and their families about palliative and end-of-life care: comfort and educational needs of nurses. Int J Palliat Nurs;21(3):109-12(2015).

21. Hou YF, et al. Nurses' knowledge and attitudes on comfort nursing care for hospitalized patients. IJNP, 20(6):573-8(2014).

22. Tripathy S, Routray PK, Mishra JC. Intensive care nurses' attitude on palliative and end of life care. Indian JCritCare Med,21(10):655(2017).

23. Partain, Daniel K., Cory Ingram, and Jacob J. Strand. "Providing appropriate end-of-life care to religious and ethnic minorities." Mayo Clin Proc. 92(1). 147- 152(2017).

24. Powazki $R$, et al. The care of the actively dying in an academic medical center: a survey of registered nurses' professional capability and comfort. Am J Hosp Palliat Med; 31(6):619-27(2014).

25. Ayed A, Sayej S, Harazneh L, Fashafsheh I, Eqtait F. The Nurses' Knowledge and Attitudes towards the Palliative Care. JEP; 6:91-99(2015).

26. Wolf LA, et al. Exploring the Management of Death: Emergency Nurses' Perceptions of Challenges and Facilitators in the Provision of End-of-Life Care in the Emergency Department. J Emerg Nurs; 41(5):e23-33(2015).

27. Bailey, Cara, and Alistair Hewison. The impact of a 'Critical Moments' workshop on undergraduate nursing students' attitudes to caring for patients at the end of life: an evaluation; J Clin Nurs; 23(2324):3555-63(2014).

\section{Tables}


Table 1

Demographic variables descriptive analysis

\begin{tabular}{|ll|}
\hline Variables & $\mathbf{N}(\%)$ \\
\hline Gender & \\
Male & $125(56.8)$ \\
Female & $95(43.2)$ \\
\hline Marital status & \\
Single & $85(39)$ \\
Married & $135(61)$ \\
\hline Educational level & \\
Diploma & $13(5.9)$ \\
Bachelor & $187(85)$ \\
Master's & $20(9.1)$ \\
\hline Work unit & \\
\hline *ICU & $131(59.5)$ \\
\hline \#Med/surg floor & $45(20.5)$ \\
\hline \$ER & $13(5.9)$ \\
Oncology/palliative & $21(9.5)$ \\
Others & $10(4.6)$ \\
\hline Had a training course in palliative or EOL care & \\
Yes & $27(12.3)$ \\
No & $193(87.7)$ \\
\hline Age/ years Mean(SD);[Range] & $29.1(5.1) ;[22-55]$ \\
\hline Experience/ Years Mean(SD);[Range] & $6.3(4.6) ;[1-30]$ \\
\hline
\end{tabular}

*ICU: intensive care unit

\#Med/Surg: medical/ surgical floor

\$ ER: emergency room 
Table 2

Descriptive statistics for range of EPCS categorical scores $(\mathrm{N}=205)$

\begin{tabular}{|llll|}
\hline Category number & \multicolumn{4}{l}{ Range of EPCS/ Categorical Scores } & N (\%)* \\
\hline $\mathbf{0}$ & Not at all & Range, 0-21 & 0 \\
\hline $\mathbf{1}$ & A little bit & Range, 22-44 & $4(2)$ \\
\hline $\mathbf{2}$ & Some & Range 45-89 & $70(34.1)$ \\
\hline $\mathbf{3}$ & Quite a bit & Range, 86-90 & $\mathbf{1 1 5 ( 5 6 . 1 )}$ \\
\hline $\mathbf{4}$ & Very much & Range, 91-112 & $16(7.8)$ \\
\hline
\end{tabular}

*: missing cases 15: some participants did not answer all the items of the scale, so we cannot calculate the total score.

Table 3

Total scores for each of EPCS subscales including (PFCC, CEV, and ECD)

\begin{tabular}{|lllll|}
\hline & $\mathbf{N}$ & Min & Max & Mean(SD) \\
\hline EPCS & 205 & 36 & 112 & $72.1(13.6)$ \\
PFCC & 209 & 18 & 48 & $31.8(6.2)$ \\
CEV & 214 & 9 & 32 & $21.9(4.4)$ \\
ECD & 214 & 5 & 32 & $18.6(5.4)$ \\
\hline
\end{tabular}

EPCS: End-of-Life Professional Caregiver Survey

PFCC: Patient and family-centered communication

CEV: Cultural and ethical values

ECD: Effective care delivery 
Table 4

Correlations between EPCS and demographic variables

\begin{tabular}{|lll|}
\hline Variables & r value & P value \\
\hline Age & 0.09 & 0.2 \\
\hline Gender & 0.13 & 0.07 \\
\hline Marital status & 0.06 & 0.7 \\
\hline Educational level & 0.04 & 0.6 \\
\hline Work unit & 0.06 & 0.4 \\
\hline Years of experience & -0.11 & 0.1 \\
\hline Attending educational training courses & $\mathbf{0 . 1 6}$ & $\mathbf{*} 0.01$ \\
\hline
\end{tabular}

Table 5

Hierarchical multiple regression model for predictors of EPCS

\begin{tabular}{|c|c|c|c|c|c|c|}
\hline variables & $\begin{array}{l}\text { Adjusted } \\
\mathrm{R}^{2}\end{array}$ & SE & $\begin{array}{l}\mathrm{R}^{2} \\
\text { change }\end{array}$ & $\begin{array}{l}\text { Standardized } \\
\text { coefficient } \\
\beta\end{array}$ & $\mathbf{P}$ & $\mathrm{Cl}$ \\
\hline Age & 0.032 & 13.4 & 0.06 & -0.05 & 0.6 & $-0.8-0.05$ \\
\hline Gender & & & & -0.12 & 0.09 & $-7.29-0.59$ \\
\hline Marital status & & & & 0.01 & 0.8 & $-3.76-4.57$ \\
\hline Work unit & & & & -0.14 & 0.04 & $-7.79--0.12$ \\
\hline Years of experience & & & & 0.09 & 0.4 & $\begin{array}{l}-0.42- \\
1.005\end{array}$ \\
\hline $\begin{array}{l}\text { Attending educational } \\
\text { training courses }\end{array}$ & & & & 0.17 & 0.02 & $1.03-12.8$ \\
\hline
\end{tabular}

SE: standard error

P: significant value

Cl: confidence interval 